DOI: https://doi.org/10.47405/mjssh.v6i4.761

\begin{tabular}{|c|c|}
\hline$x=1+2$ & Malaysian Journal of Social Sciences and Humanities (MJSSH) \\
\hline Malaysian Journal of & Volume 6, Issue 4, April 2021 \\
\hline (MJ-ssH) & e-ISSN : 2504-8562 \\
\hline & $\begin{array}{l}\text { Journal home page: } \\
\text { www.msocialsciences.com }\end{array}$ \\
\hline
\end{tabular}

\title{
Penggunaan E-Pembelajaran dan Kesannya Terhadap Kesejahteraan Kakitangan Akademik di Institusi Pengajian Tinggi di Sabah
}

\author{
Kee. Y. Sabariah Bte Kee Mohd Yussof ${ }^{1}$, Mahadirin Ahmad', Jalihah Md Shah"1, Jurry Foo', \\ Ramlah Daud1, Md Hafizi², Liew Thor Seng3 \\ 1Fakulti Sains Sosial dan Kemanusiaan, Universiti Malaysia Sabah, Jalan UMS, 88400 Kota Kinabalu, Sabah, \\ 2Fakulti Kewangan Antarabangsa Labuan, Universiti Malaysia Sabah, Kampus Antarabangsa Labuan, Jalan \\ Sungai Pagar 87000, W. P. Labuan Malaysia, \\ ${ }^{3}$ Fakulti Sains dan Sumber Alam, Universiti Malaysia Sabah, Jalan UMS, 88400 Kota Kinabalu, Sabah, Malaysia
}

Correspondence: Kee.Y. Sabariah Bte Kee Mohd Yussof (keesabariah@ums.edu.my)

\begin{abstract}
Abstrak
E-Pembelajaran adalah kaedah pembelajaran dengan menggunakan informasi teknologi dalam pemindahan pengetahuan, pembelajaran dan latihan dalam pendidikan moden. Sejajar dengan perkembangan teknologi dan dunia tanpa sempadan, pelbagai usaha dilakukan untuk memperkenalkan sistem E-Pembelajaran dalam sistem pembelajaran universiti di Malaysia. Pemindahan pengetahuan, aktiviti pembelajaran, kuliah dan tutorial tidak terhad kepada pertemuan bersemuka atau kuliah secara tradisional antara para pensyarah dan pelajar malah boleh dilakukan melalui blanded learning (BL). Walau bagaimanapun perkembangan ini mempengaruhi kesejahteraan dalam pekerjaan kakitangan akademik. Kajian rintis (pendekatan kuantitatif) yang dilakukan dalam kalangan kakitangan akademik di Institusi Pengajian Tinggi (IPT) awam dan swasta di Sabah menunjukkan Model Unified Theory of Acceptance And Use Of Technology (UTAUT) boleh digunakan sebagai peramal kepada tingkah laku menggunakan e-pembelajaran kakitangan akademik. Hasil kajian mendapati faktor kondisi kemudahan dan sokongan peralatan teknologi mempunyai pengaruh yang signifikan terhadap penerimaan penggunaan E-Pembelajaran dalam aktiviti pembelajaran harian. Walau bagaimanapun kajian ini mendapati amalan E-Pembelajaran mempengaruhi kebimbangan kakitangan akademik dan menerbitkan perasaan takut ketinggalan dalam memahami sistem teknologi pendidikan pada masa kini. Kajian ini membuka jalan kepada penyelidikan yang berkait rapat dengan penerimaan teknologi sejajar dengan keperluan pada masa kini.
\end{abstract}

Kata kunci: Model UTAUT, e-pembelajaran, kesejahteraan pekerja, takut ketinggalan

\section{The Usage of E-Learning and its Impact to Academics Staff Wellbeing in Higher Learning Institutions in Sabah}

\begin{abstract}
E-Learning is a method of learning in which it uses information technology in knowledge transfer, learning and training in modern education. This is in line with the development of nowadays technology and its borderless world, thus various efforts have been made to introduce the E-Learning system in the learning system of universities in Malaysia. Knowledge transfer, learning activities, lectures and tutorials are not limited to face - to - face or traditional ways of meetings or lectures between lecturers and students, this is because it can even be done through blended learning (BL).
\end{abstract}


However these developments affect the wellbeing of the academic staff employment. A pilot study based on quantitative approach have been conducted among academic staff in public and private Higher Learning Institutions (IPT) in Sabah showed that the Unified Theory Model Of Acceptance And Use Of Technology (UTAUT) can be used as a predictor of behavior usage of E-learning among academic staff. The results of this study shows that the factors of facility conditions and technological equipment support have a significant influence on the acceptance of the usage of E-Learning in daily learning activities. However the findings of this studies also shows that E-Learning practices have a significant influence to the anxiety of academic staff such as fear of missing in understanding nowadays education technology system. Thus this study paves the way to research that is related to the adoption of technology in line with the current needs in Higher Learning Institution.

Keywords: UTAUT model, e-learning, employee wellbeing, fear of missing

\section{Pengenalan}

E-Pembelajaran adalah kaedah pembelajaran dengan menggunakan informasi teknologi dalam pemindahan pengetahuan, pembelajaran dan latihan dalam pendidikan moden. Ramakrisnan, Yahya, Hasrol dan Aziz (2012) menyatakan E-Pembelajaran melibatkan komunikasi secara elektronik yang berkait rapat dengan penggunaan internet dan komputer. E-Pembelajaran melibatkan penyampaian ilmu secara elektronik seperti CD Roms, video conferencing, website, email dan portal EPembelajaran. Pembelajaran dikaitkan dengan metod digital, interaksi secara atas talian di antara pelajar dan kakitangan akademik. Dalam memastikan bidang akademik selari dengan tuntutan revolusi 4.0, bidang akademik menggalakkan pembelajaran teradun agar aktiviti pembelajaran selari dengan generasi pada masa kini yang lebih suka menggunakan teknologi dalam aktiviti harian mereka. Kebanyakan universiti di Malaysia mempunyai portal E-Pembelajaran untuk memudahkan hubungan dan interaksi secara digital di antara pelajar dan pensyarah atau kakitangan akademik. Namun adakah perkembangan teknologi dalam bidang akademik ini boleh diterima oleh semua pengamal dalam Institusi Pengajian Tinggi (IPT). Kajian ini menggunakan Model Unified Theory of Acceptance And Use of Technology (UTAUT) untuk menilai persepsi penerimaan kakitangan akademik daripada aspek jangkaan prestasi dan jangkaan usaha terhadap E-Pembelajaran. Persepsi mereka terhadap pengaruh sosial dan kondisi kemudahan yang disediakan oleh pihak universiti. Dengan amalan dan penerimaan teknologi melalui E-Pembelajaran, kajian ini mengenal pasti pengaruhnya terhadap kesejahteraan pekerjaan yang meliputi perasaan gembira, selesa, senang dan tanggapan yang baik terhadap pekerjaannya dengan mengetengahkan salah satu elemen iaitu perasaan takut ketinggalan.

\section{Pernyataan Masalah dan Objektif Kajian}

Perkembangan teknologi menuntut perubahan dalam sistem pendidikan di Malaysia dan mempengaruhi aktiviti pembelajaran dan pengajaran di IPT. Walau bagaimanapun pendidikan tinggi masih ketinggalan dalam sistem teknologi, dimana terdapat kekurangan kemahiran dan pengetahuan yang tidak seiring dengan era milenium pada masa kini (Bond \& Goodchild, 2013). Rubiah Omar dan Jamilah Hj.Ahmad (2009) menjelaskan IPT di Malaysia masih belum mencapai tahap penerimaan yang baik terhadap E-Pembelajaran. Sehubungan dengan itu kakitangan akademik menerima kesan kesejahteraan dalam pekerjaannya akibat perkembangan terbaru dalam tugas harian iaitu peralihan daripada pembelajaran bersemuka atau tradisional kepada pembelajaran atas talian. Ramakrisnan et al. (2012) mendapati terdapat individu yang menolak kehadiran teknologi baru malah berhadapan dengan ketakutan untuk berubah dan menerima teknologi yang mengubah cara pendidikan secara tradisional. Dalam kajian berkaitan teknologi, pekerja mengalami desakan sosial daripada persekitaran kerja kerana bimbang dan wujud perasaan takut ketinggalan terhadap perkembangan teknologi (Ishak \& Sarkowi, 2018). Kakitangan akademik mula merasa tertekan, bebanan kerja meningkat kerana terpaksa belajar mengendalikan teknologi melalui portal yang disediakan dan memperuntukkan lebih banyak masa untuk menyediakan bahan-bahan pengajaran. Tidak kurang juga kakitangan akademik yang lebih suka cara penyampaian yang tradisional dan bersemuka kerana tidak yakin pelajar 
memahami apa yang diajar oleh mereka secara maya atau melalui interaksi E-Pembelajaran. Berdasarkan permasalahan kajian tersebut, timbul persoalan tentang tahap amalan E-Pembelajaran dalam kalangan kakitangan akademik di IPT Sabah dan kesannya terhadap salah satu elemen kesejahteraan pekerja iaitu perasaan takut ketinggalan. Model Unified Theory of Acceptance And Use of Technology (UTAUT) digunakan untuk meramal tingkah laku dan persepsi kakitangan akademik terhadap E -Pembelajaran. Daripada permasalahan kajian tersebut maka objektif kajian adalah seperti berikut:

i. Mengkaji tahap amalan E-Pembelajaran dalam kalangan kakitangan akademik di IPT Sabah.

ii. Mengkaji pengaruh amalan E-Pembelajaran terhadap perasaan takut ketinggalan.

\section{Sorotan Literatur}

\section{Konsep E-Pembelajaran}

Konsep E-Pembelajaran merujuk kepada pembelajaran menggunakan informasi teknologi dalam pendidikan dan latihan melalui rangkaian komputer dan internet, TV interaktif atau aplikasi digital. Ia juga meliputi ciri-ciri multimedia seperti audio, visual dan perbincangan atas talian (Cidral, Oliveira, Di Felice, \& Aparicio, 2018) Ramakrisnan et al., (2012) mendefinisikan E-Pembelajaran adalah pendidikan yang menggunakan metod elektronik seperti CD Roms, video, laman web dan email. EPembelajaran menggunakan aplikasi dan peralatan digital dan merupakan pembelajaran yang interaktif, berinformasi dan melibatkan interaksi di alam maya antara pelajar dan guru/tenaga pengajar. Oleh itu, E-Pembelajaran adalah proses pembelajaran yang tidak bersemuka antara pelajar dan pensyarah/guru namun menggunakan pelbagai medium atas talian, informasi dan komunikasi teknologi digital dengan menggunakan internet dan peralatan elektronik.

\section{Model Unified Theory of Acceptance And Use of Technology (UTAUT)}

UTAUT adalah salah satu model penerimaan teknologi terkini yang dikembangkan oleh Venkatesh pada tahun 2003. Venkatesh et al. (2016) menyatakan model ini adalah gabungan daripada lapan teori penerimaan teknologi yang digabungkan dalam satu model. Model ini menggabungkan theory of reasoned action (TRA), technology acceptance model (TAM), motivational model (MM), theory of planned behavior (TPB), combined TAM dan TPB, model of PC utilization (MPTU), innovation diffusion theory (IDT), dan social cognitive theory (SCT). Di mana Venkatesh (2003) melihat model yang dibentuknya lebih baik daripada teori yang berasingan dan dapat menggambarkan kecenderungan pengguna menerima kehadiran teknologi yang baru. Daripada lapan teori tersebut, tujuh konstruk telah dibentuk iaitu niat untuk berperilaku (behavioral intention), perilaku untuk menggunakan suatu teknologi (use behavior) jangkaan prestasi (performance expectancy), jangkaan usaha (effort expectancy), pengaruh sosial (social influence) dan kondisi kemudahan (facilitating conditions). Namun kajian ini hanya memfokuskan kepada jangkaan prestasi, jangkaan usaha, pengaruh sosial, kondisi kemudahan dan niat untuk menggunakan E-Pembelajaran. Persepsi terhadap jangkaan prestasi merupakan persepsi yang menilai sama ada teknologi itu memberi kebaikan kepada pengguna dari segi keberkesanan dan kecekapan pengajaran. Dimensi kedua iaitu persepsi terhadap jangkaan usaha di mana persepsi tentang penggunaan teknologi pembelajaran mudah dipelajari dan difahami melalui usaha yang dilakukan oleh pengguna. Manakala pengaruh sosial adalah individu dan persekitaran yang mempengaruhi penggunaan E- Pembelajaran dan kemudahan adalah persepsi tentang penyediaan sistem sokongan terhadap penggunaan E-Pembelajaran.

Model ini telah digunakan untuk meramal penggunaan dan amalan teknologi dan Sedana (2010) pernah menggunakan model ini untuk menilai perspektif penerimaan E-Pembelajaran terhadap pelajar. Namun, model ini masih kurang digunakan dalam kajian yang meramal tingkah laku penerimaan EPembelajaran dalam kalangan kakitangan akademik. Tarafdar, D'Arcy, Turel dan Gupta (2015) menilai individu yang berbeza mempunyai tahap penerimaan yang berbeza terhadap E-Pembelajaran. Malah untuk menjayakan E-Pembelajaran memerlukan sokongan dan dorongan yang kuat daripada semua pihak iaitu pihak pengurusan, pelajar dan kakitangan akademik. 


\section{Hubungan antara amalan E-Pembelajaran dan sindrom takut ketinggalan}

Kesejahteraan pekerja merujuk kepada rasa sejahtera yang diperoleh oleh pekerja daripada pekerjaan yang mereka lakukan di mana ia berkaitan dengan perasaan pekerja secara umum, nilai intrinsik dan ekstrinsik yang membentuk nilai pekerjaan tersebut (Page, Vella-brodrick, \& Vella-brodrick, 2009). Kebimbangan dan perasaan takut ketinggalan adalah sebahagian daripada elemen intrinsik kesejahteraan pekerja. Kajian oleh Bond dan Goodchild (2013) mendapati kebimbangan wujud dan merasa kurang moden dan maju kehadapan di mana sesetengah kakitangan akademik beranggapan apabila berada dalam talian akan wujud suatu situasi yang membazir masa dengan menghadap komputer, merasa tidak selesa, cemas dan merasakan seolah-olah memutuskan hubungan yang akrab dengan pelajar. Sehubungan dengan itu, kakitangan akademik dalam kajian mereka memberi persepsi bahawa intimasi dan hubungan bersama pelajar akan berkurangan dan mereka takut akan gagal memberikan yang terbaik dalam proses pengajarannya.

Kajian oleh Rafnsdottir dan Gudmundsdottir (2004) mendapati kewujudan satu sistem teknologi dalam organisasi memberi impak kepada kesejahteraan hidup pekerja. Pekerja dalam persekitaran teknologi yang tinggi berhadapan dengan masalah kesihatan dan mengalami tekanan, kurang ceria akibat keletihan dan seolah-olah bekerja selama 24 jam sehari. Teknologi yang boleh dicapai pada bila-bila masa menyebabkan pekerja berasa tidak ada jalan pemisah antara pekerjaan dan kehidupannya setiap hari. Kajian oleh Ishak dan Sarkowi (2018) mendapati kewujudan teknologi menyebabkan pekerja mengalami tekanan, kelesuan, desakan sosial dan sindrom takut ketinggalan. Ini kerana maklumat yang diterima dan komunikasi dalam talian sukar dikawal dan mengganggu kehidupan seharian. Walaupun kajian sebelum ini mengaitkan sindrom takut ketinggalan dengan penggunaan media sosial namun tidak mustahil situasi yang sama wujud dalam penggunaan teknologi yang lain (Przybylski, Murayama, Dehaan \& Gladwell,2013).

Rajah 1: Kerangka Konseptual Model UTAUT dan pengaruhnya terhadap Perasaan Takut Ketinggalan

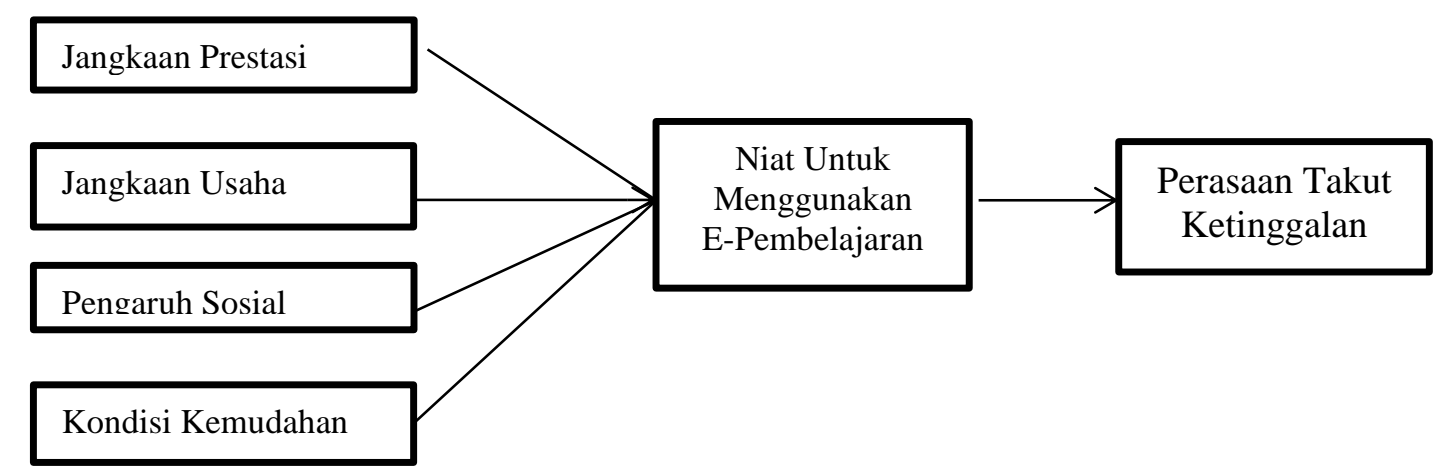

\section{Metod Kajian}

Kajian ini merupakan kajian rintis yang melibatkan 30 orang responden yang terdiri daripada kakitangan akademik di institusi pengajian tinggi awam dan swasta di Kota Kinabalu. Penyelidikan ini menggunakan pendekatan kuantitatif dengan menggunakan soal selidik sebagai instrumen kajian. Model UTAUT oleh Venkeatesh et al. (2016) mengandungi empat (4) dimensi dan enam belas (16) item. Niat untuk menggunakan E-Pembelajaran sebanyak 5 item dan item takut ketinggalan mengandungi 12 item soalan yang diadaptasi dari Przybylski, Murayama, Dehaan dan Gladwell (2013). Kesemua item ini diukur pada peringkat individu dan berdasarkan skala likert lima (5) mata di mana $1=$ sangat tidak setuju hingga $5=$ sangat setuju. Data dianalisis dengan menggunakan perisian Statistical Package for Social Science (SPSS) versi 25. Statistik deskriptif dan analisis regresi mudah digunakan untuk menganalisis data yang diperoleh. 


\section{Hasil Kajian}

Nilai kebolehpercayaan kurang dari 0.6 adalah lemah, manakala nilai 0.6 hingga 0.7 menunjukkan soal selidik yang diuji mempunyai nilai kebolehpercayaan yang boleh diterima, manakala 0.8 hingga 1 menunjukkan nilai kebolehpercayaan dan kesahan yang tinggi (Sekaran \& Bougie, 2016). Keseluruhan instrumen mempunyai nilai kebolehpercayaan yang baik, maka kajian ini boleh dianalisis selanjutnya.

Jadual 1: Keputusan analisis ujian kebolehpercayaan

\begin{tabular}{lll}
\hline Faktor & Jumlah Item & Nilai Alpha \\
\hline Jangkaan prestasi & 4 & 0.724 \\
Jangkaan usaha & 4 & 0.937 \\
Pengaruh Sosial & 4 & 0.737 \\
Keadaan Kemudahan & 4 & 0.591 \\
Niat untuk menggunakan E-Pembelajaran & 5 & 0.640 \\
Perasaan Takut Ketinggalan & 12 & 0.831 \\
\hline
\end{tabular}

Jadual 2: Demografi Responden

\begin{tabular}{lll}
\hline Ciri Umum Responden & Ciri Khusus Responden & Bil/Peratus \\
\hline Jantina & Lelaki & $7(23 \%)$ \\
& Wanita & $23(77 \%)$ \\
Jawatan & Pensyarah & $17(57 \%)$ \\
& Pensyarah Kanan & $13(43 \%)$ \\
Tempoh berkhidmat dalam & 1 hingga 5 Tahun & $8(27 \%)$ \\
Organisasi & 6 hingga 10 Tahun & $9(30 \%)$ \\
& 11 hingga 15 Tahun & $7(23 \%)$ \\
& 16 hingga 20 Tahun & $4(13 \%)$ \\
Institusi Pengajian Tinggi & 21 hingga 25 Tahun & $2(7 \%)$ \\
& IPT AWAM & $21(70 \%)$ \\
& IPT SWASTA & $9(30 \%)$ \\
\hline
\end{tabular}

Jadual diatas menunjukkan demografi responden yang terlibat dalam kajian rintis ini di mana, pensyarah wanita lebih ramai berbanding pensyarah lelaki. Berdasarkan jawatan terdapat dua kategori jawatan iaitu pensyarah kanan dan pensyarah. Di mana 57 peratus menunjukkan pensyarah dan 43 peratus adalah pensyarah kanan. Responden dalam kajian ini terdiri daripada IPT awam dan swasta iaitu IPT awam mewakili 70 peratus dan IPT swasta mewakili 30 peratus. Dari segi tempoh perkhidmatan, 6 hingga 10 tahun mewakili 30 peratus, perkhidmatan 1 hingga 5 tahun sebanyak 27 peratus dan 11 hingga 15 tahun mewakili 23 peratus. Kebanyakan responden mempunyai pengalaman bekerja yang lama sebagai ahli akademik. Sebahagian daripada kakitangan akademik mempunyai pengalaman dan merupakan pensyarah senior dan berjawatan sebagai pensyarah kanan.

Jadual 3: Tahap Penggunaan E-Pembelajaran, Niat Untuk Menggunakan E Pembelajaran dan sindrom Takut Ketinggalan

\begin{tabular}{lll}
\hline Pemboleh ubah & Nilai Min & Tahap \\
\hline Jangkaan Prestasi & 3.31 & Sederhana \\
Jangkaan Usaha & 3.17 & Sederhana \\
Pengaruh Sosial & 3.95 & Tinggi \\
Kondisi Kemudahan & 3.49 & Sederhana \\
Niat Untuk Menggunakan E & 3.73 & Tinggi \\
Pembelajaran & & \\
Perasaan Takut Ketinggalan & 3.11 & Sederhana \\
\hline
\end{tabular}


Jadual 4 : Penerangan Tahap Skor Min

\begin{tabular}{cc}
\hline Pengelasan Skor Min & Tahap Skor \\
\hline $1.00-2.33$ & Rendah \\
$2.34-3.67$ & Sederhana \\
$3.68-5.00$ & Tinggi \\
\hline
\end{tabular}

Sumber: Mohd Najib (1999)

Jadual 5: Keputusan Analisis Regresi, pengaruh jangkaan prestasi, jangkaan usaha, pengaruh sosial dan kondisi kemudahan terhadap niat untuk menggunakan E-Pembelajaran

\begin{tabular}{lll}
\hline Model & Pekali Piawai $\beta$ & Sig \\
\hline Jangkaan Prestasi & .161 & .437 \\
Jangkaan Usaha & .082 & .772 \\
Pengaruh Sosial & .364 & .163 \\
Kondisi Kemudahan & .514 & .002 \\
$\mathrm{R}^{2}$ & .423. & \\
$\mathrm{~F}$ & 4.58 & \\
Sig & .005 & \\
\hline
\end{tabular}

.a. Peramal dalam Model (Tetap): Niat untuk menggunakan E Pembelajaran.

.b. Bersandar : Model UTAUT(Jangkaan prestasi,jangkaan usaha,pengaruh sosial,kondisi kemudahan)

Daripada jadual ini menunjukkan model kajian adalah signifikan di mana Model UTAUT boleh digunakan untuk meramal niat untuk menggunakan E-Pembelajaran. Sumbangan model kajian adalah $\left(\mathrm{R}^{2}=.423, \mathrm{k}=.005\right) 43$ peratus. Namun hanya kondisi kemudahan sahaja yang mempengaruhi niat kakitangan akademik menggunakan E-Pembelajaran iaitu 51 peratus dan signifikan. Ini menunjukkan dengan adanya kemudahan yang disediakan, maka kakitangan akademik akan mempunyai kecenderungan untuk menggunakan E-Pembelajaran. Jika kemudahan yang menyokong EPembelajaran ditingkatkan, maka ia akan meningkatkan niat menggunakan E-Pembelajaran sebanyak 51 peratus.

Jadual 6: Keputusan Analisi Regresi, pengaruh jangkaan prestasi, jangkaan usaha, pengaruh sosial dan kondisi kemudahan terhadap takut ketinggalan

\begin{tabular}{lll}
\hline Model & Pekali Piawai $\boldsymbol{\beta}$ & Sig \\
\hline Jangkaan Prestasi & .309 & .164 \\
Jangkaan Usaha & .745 & .001 \\
Pengaruh Sosial & .688 & .000 \\
Kondisi Kemudahan & .359 & .114 \\
$\mathrm{R}^{2}$ & .353. & \\
$\mathrm{~F}$ & 3.407 & \\
Sig & .004 & \\
\hline
\end{tabular}

.a. Peramal dalam Model (Tetap): Perasaan Takut Ketinggalan.

. b. Pemboleh Ubah Bersandar : Model UTAUT(Jangkaan prestasi,jangkaan usaha,pengaruh sosial,kondisi kemudahan)

Berdasarkan jadual 6 menunjukkan model kajian UTAUT boleh digunakan untuk meramal kesejahteraan pekerja dan dalam konteks ini adalah perasaan takut ketinggalan. Sumbangan model kajian adalah $\left(\mathrm{R}^{2}=.353, \mathrm{k}=.004\right)$ iaitu 35 peratus. Faktor dominan yang mempengaruhi perasaan takut ketinggalan ini adalah jangkaan usaha dan faktor kedua yang signifikan mempengaruhi perasaan takut ketinggalan adalah pengaruh sosial. Dapatan kajian ini menunjukkan jika usaha menggunakan EPembelajaran dibuat oleh kakitangan akademik maka ia akan mengurangkan rasa takut ketinggalan 
dan pengaruh sosial iaitu persekitaran kerja, rakan sekerja, pihak pengurusan dan pelajar menyebabkan mereka mempunyai perasaan takut ketinggalan. Maka perkaitan antara dua pemboleh ubah dalam Model UTAUT iaitu jangkaan usaha dan pengaruh sosial sangat mempengaruhi kesejahteraan pekerja dalam penggunaan teknologi di tempat kerja.

\section{Perbincangan Kajian}

Hasil daripada kajian rintis dalam kalangan kakitangan akademik di IPT awam dan swasta ini mendapati Model UTAUT boleh digunakan untuk meramal tingkah laku kakitangan akademik dalam menerima dan meramal penggunaan E-Pembelajaran. Mereka mempunyai niat untuk menggunakan medium ini apabila kemudahan sokongan yang diperlukan dalam E-Pembelajaran ditambah baik. Ini menunjukkan pihak universiti perlulah menyediakan kemudahan E-Pembelajaran yang dapat menyokong penggunaan mereka. Kemudahan seperti kelajuan capaian internet di Universiti dan kolej kediaman pelajar, kecapaian maklumat dalam membentuk E-Pembelajaran dan peralatan seperti komputer, alat perakam suara dan kamera yang menyokong seseorang itu berinteraksi menggunakan $\mathrm{E}$ Pembelajaran haruslah ditingkatkan. Selain itu berdasarkan data deskriptif yang diperoleh, keseluruhan kakitangan akademik memberi persepsi bahawa mereka memerlukan sistem sokongan iaitu individu yang boleh membantu memberi tunjuk ajar berkaitan teknikal apabila diperlukan. Hasil kajian ini menyokong dapatan kajian oleh Tarafdar, D'Arcy, Turel dan Gupta (2015) yang menyatakan pengguna teknologi memerlukan sokongan dan kerjasama daripada pihak pengurusan dan rakan sekerja untuk mengadaptasi teknologi dalam pekerjaan harian mereka. Latihan dan perkongsian pengetahuan dalam penggunaan teknologi baru sangat membantu pekerja dalam organisasi untuk menerima perubahan. Dalam konteks ini, perubahan daripada kaedah pembelajaran tradisional dan bersemuka kepada pembelajaran atas talian.

Daripada persepsi kakitangan akademik dalam kajian ini, menunjukkan perasaan takut ketinggalan dengan perkembangan teknologi adalah wujud pada tahap yang sederhana. Berdasarkan analisis deskriptif menunjukkan nilai min tertinggi pada item kewujudan perasaan cemas apabila tidak mengetahui sesuatu dalam sistem dan portal E-Pembelajaran dan merasa terkesan dengan gurauan rakan sekerja tentang E-Pembelajaran. Situasi ini menunjukkan keseluruhan kakitangan akademik mengambil berat akan kepentingan E-Pembelajaran walaupun ia disampaikan melalui gurauan antara rakan sekerja. Perasaan cemas menghantui mereka apabila mereka merasakan agak ketinggalan dan tidak tahu menahu tentang perkembangan E-Pembelajaran atau perubahan yang berlaku dalam sistem ini.

Faktor yang dominan melalui Model UTAUT adalah jangkaan usaha yang mempengaruhi perasaan takut ketinggalan. Melalui analisis deskriptif mendapati keseluruhan responden mempunyai usaha untuk mahir dalam E-Pembelajaran dan jika mereka tidak mampu berusaha untuk mahir, kecenderungan untuk merasa ketinggalan dengan teknologi adalah tinggi. Manakala faktor dominan yang kedua adalah pengaruh sosial, di mana keseluruhan responden memberi persepsi bahawa universiti menyokong penggunaan E- Pembelajaran. Pihak universiti menyediakan bantuan untuk membolehkan kakitangan akademik mahir dalam teknologi. Pihak universiti, rakan sekerja dan pelajar merupakan desakan kepada mereka untuk menggunakan E-Pembelajaran. Sebaliknya jika mereka gagal memenuhi keperluan E-Pembelajaran maka ia akan meningkatkan lagi perasaan takut ketinggalan. Tambahan pula pihak universiti telah menyediakan kemudahan latihan dari masa ke semasa dalam meningkatkan kemahiran E-Pembelajaran di universiti. Hasil kajian ini menyokong kajian Bond dan Goodchild (2013) yang mendapati kebimbangan akan wujud apabila pekerja merasa mereka ketinggalan dengan arus kemodenan dan merasa tidak selesa dengan teknologi yang harus mereka pelajari. Dapatan kajian dalam konteks di Sabah ini juga membenarkan dapatan kajian Ishak dan Sarkowi (2018) yang menyatakan desakan sosial itu menyebabkan mereka merasa tidak selesa kerana dibebani dengan teknologi. Walau bagaimanapun untuk berada seiringan dengan perubahan teknologi dan pembelajaran gaya baru, perasaan itu perlu diatasi bersama usaha untuk bekerja dan berinteraksi dengan teknologi. 


\section{Kesimpulan}

Kajian ini telah menyumbang kepada perkembangan teori dan model UTAUT dalam konteks penerimaan teknologi dalam kalangan kakitangan akademik melalui E-Pembelajaran. Model UTAUT yang terdiri daripada empat (4) dimensi dalam kajian ini iaitu jangkaan prestasi, jangkaan usaha menggunakan E-Pembelajaran, pengaruh sosial dan kondisi kemudahan merupakan model kajian yang signifikan untuk meramal niat menggunakan E-Pembelajaran. Daripada empat (4) dimensi terdapat satu dimensi iaitu kondisi kemudahan yang mempengaruhi secara signifikan terhadap niat untuk menggunakan E-Pembelajaran. Ini menunjukkan apabila kemudahan yang menyokong EPembelajaran adalah cukup dan mudah diperolehi maka kecenderungan menggunakan E-Pembelajaran dalam pengajaran dan pembelajaran akan meningkat. Model UTAUT juga mempunyai perkaitan yang rapat dengan kesejahteraan pekerja, di mana kegagalan menggunakan E-Pembelajaran menyebabkan pekerja merasa takut ketinggalan. Dalam kajian ini dua faktor iaitu jangkaan usaha dan pengaruh sosial mempunyai pengaruh yang signifikan terhadap perasaan takut ketinggalan dalam era teknologi dan E-Pembelajaran. Kajian ini tidak menolak bahawa kewujudan teknologi melalui E-Pembelajaran mengganggu kesejahteraan hidup pekerja. Secara praktikalnya kajian ini menyumbang kepada satu dapatan kajian yang memberi impak kepada organisasi atau institusi akademik. Perubahan dalam organisasi perlu dilakukan secara berperingkat dan pihak pengurusan universiti harus memberi sokongan dan motivasi yang berterusan agar pekerja tidak takut kepada perubahan dan teknologi. Usaha untuk memperbaiki kemudahan yang menyokong pembelajaran atas talian harus diberi perhatian agar ia tidak menjadi punca kepada niat untuk tidak menggunakan E-Pembelajaran pada masa kini. Walau bagaimanapun kajian ini merupakan kajian rintis yang perlu diperbaiki pada masa akan datang. Beberapa elemen kesejahteraan pekerja seperti kepuasan pekerja, prestasi pekerja dan tekanan kerja perlu diambil kira dalam kajian sebenar dan pemboleh ubah demografi seperti jantina, tempoh perkhidmatan dan jawatan hendaklah dikaitkan dalam perbincangan pada kajian di masa hadapan.

\section{Penghargaan}

Hasil penulisan ini adalah sebahagian daripada geran penyelidikan di bawah Skim Dana Nic (SDN). Pengkaji merakamkan setinggi-tinggi penghargaan dan terima kasih kepada pihak Universiti Malaysia Sabah diatas pembiayaan kajian ini.

\section{Rujukan}

Bond, E., \& Goodchild, T. (2013). Paradigms, paradoxes and professionalism: An exploration of lecturers' perspectives on technology enhanced learning. Journal of Applied Research in Higher Education, 5(1), 72-83.

Cidral, W. A., Oliveira, T., Di Felice, M., \& Aparicio, M. (2018). E-learning success determinants: Brazilian empirical study. Computers and Education, 122, 273-290.

Ishak dan Sarkowi (2018).Tekanan digital; Kesan Beban Komunikasi Dan Multitugas Internet Terhadap Kesejahteraan Psikologi Penjawat Awam Di Malaysia. Kertas Kerja dibentangkan di International Malaysian Studies Conference (MSC11), Langkawi.Kedah

Mohd Najib Abdul Ghaffar. (1999). Kaedah Penyelidikan Pendidikan. Skudai: Penerbitan. Universiti Teknologi Malaysia.

Page, K. M., Vella-brodrick, D. A., \& Vella-brodrick, K. M. P. D. A. (2009). The 'What ', ' Why ' and 'How' of Employee Well-Being: Social Indicators Research, 90(3), 441-458.

Przybylski, A. K., Murayama, K., Dehaan, C. R., \& Gladwell, V. (2013). Com puters in Human Behavior Motivational, emotional, and behavioral correlates of fear of missing out. Computers in Human Behavior, 29(4), 1841-1848.

Rafnsdottir, G. L., \& Gudmundsdottir, M. L. (2004). New technology and its impact on well being. Work, 22(1), 31-39. 
DOI: https://doi.org/10.47405/mjssh.v6i4.761

Ramakrisnan, P., Yahya, Y. B., Hasrol, M. N. H., \& Aziz, A. A. (2012). Blended Learning: A Suitable Framework For E-Learning In Higher Education. Procedia - Social and Behavioral Sciences, 67, $513-526$

Rubiah Omar dan Jamilah Hj.Ahmad. (2009). Kesedaran , Penilaian dan Penerimaan e-Pembelajaran dalam Kalangan Ahli Akademik ( Awareness , Evaluation and Acceptance of e-Learning Among, 34(1), 155-172.

Sekaran Uma \& Bougie Roger. (2010). Research Methods for Business A Skill Building Approach (5th Editio). United Kingdom: Wiley.

Sedana, I. G. N. (2010). UTAUT Model for Understanding Learning Management System, 2(2), 27 32.

Tarafdar, M., D’Arcy, J., Turel, O., \& Gupta, A. (2015). The Dark Side of Information Technology. MIT Sloan Management Review, 8(4), 395-402.

Venkatesh, V., Thong, J. Y. L., Statistics, B., Xu, X., \& Acceptance, T. (2016). Unified Theory of Acceptance and Use of Technology: A Synthesis and the Road Ahead, 17(5), 328-376. 